\title{
PENGEMBANGAN JATI DIRI DARI PERSPEKTIF PENDIDIKAN KRISTEN
}

\section{IBET PATIUNG}

Lembaga: IAKN Toraja ,posel:rinjanipatiung@gmail.com

\begin{abstract}
Abstrack :
From this article I will reflect on the development of identity from a Christian perspective. The purpose of this article is to show that self development is very important. The rush in modern life that moves fast,often makes us forget ourselves and lose control. Therefore chirstian education must play a role in the formation of ones's identity. Education does not yet deserve to be called education if it ignores the formation of one's character. Identity which is a characteristic that unites in a person, that is, it must reflect the real cash towards fellow human beings.
\end{abstract}

Abstrak:

Dari artikel ini saya akan merefleksikan tentang pengembangan jati diri perspektif Kristen. Tujuan dari artikel ini adalah untuk menunjukkan bahwa pengembangan jati diri sangatlah penting. ketergesaan dalam kehidupan modern yang bergerak serba cepat,seringkali membuat kita melupakan diri sendiri dan kehilangan kendali. Oleh Karena itu pendidikan Kristen haruslah berperan dalam pembentukan jati diri seseorang. Pendidikan tidak belum pantas disebut pendidikan apabila mengabaikan pembentukan karakter seseorang. Jati diri yang merupakan ciri yang menyatu dalam diri seseorang,harus mencerminkan kasih yang sesungguhnya terhadap sesama manusia. 


\section{A. Latar Belakang}

Pendidikan iman sejatinya bukan satu-satunya diperoleh melalui pendekatan sekolah formal dalam membangun jati diri seseorang dalam pendidikan kristen. Fakta adalah iman lebih dominan diperoleh (dipelajari) justru melalui budaya; dan secara konkrit lebih banyak melalui keteladanan dan interelasi individual. Dengan kata lain,kepercayaan atau iman lebih dipengaruhi melalui pembentukan kultur.pengembangan jati diri seseorang dan Pendidikan sekolah formal bukan jaminan bagi pendidikan iman. Artinya pemosisian diri secara sturktural cenderung mempertahankan kemapanan atau anti perubahan. ${ }^{1}$

Perilaku manusia lebih banyak berfungsi karena dibentuk oleh pengamatan dan dipengaruhi oleh proses meniru perilaku orang lain. Anak-anak melihat bagaimana orangtuanya berperilaku selanjutnya meniru lanjut perilaku tersebut. Peniruan dalam tulisan ini,diberi makna positif pada peniruan sebagai salah satu proses belajar dalam totalitas kehidupan anak,baik di sekolah,di rumah,dengan hal itu, maka setiap orangtua perlu selektif dalam memilih sekolah untuk anaknya, dalam hal ini sekolah yang benar-benar menyenangi siswanya,sekolah yang memberi kemungkinan interaksi siswa dan guru yang memadai. $^{2}$

\section{B. Perumusan Masalah}

Merosotnya Pengembangan jati diri seseorang itu dipengaruhi oleh adanya berbagai hal khususnya perkembangan teknologi. Dan mengenai hal ini di situlah pendidikan Kristen hendaknya melihat bagaimana perananya dalam pengembangan potensi jati diri seseorang di tengah-tengah perkembangan

\footnotetext{
${ }^{1}$ Rannu Sanderan, “DISIPLIN ASKETISME DAN HARMONI KONTRIBUSI DISIPLIN DIRI BAGI PENGEMBANGAN PENDIDIKAN KRISTEN" (n.d.).

${ }^{2}$ Rannu Sanderan, "Stratifikasi Sosial Kepemimpinan Tradisoanal Dalam Dinamika Demokrasi Modern" (n.d.).
} 
dunia yang pesat ini.

C. Batasan Masalah

Mengenai pegembangan potensi jati diri seseorang yang di tinjau dari persepektif krristen. Dan dalam penelitian ini hanya dibatasi pada pokok tentang bagaimana peran pendidikan Kristen dalam pengembangan jati diri seseorang

D. Pembahasan

1. Pentingnya Pengembangan Jati Diri Seseorang

Pendidikan sebagai sebuah proses dalam pengembangan jati diri seseorang dan kini ditantang untuk dapat menginternalisasi makna dan berbagai perubahan yang mendasar menyangkut orientasi cara pandang tersebut. Untuk itu,sekarang ini sangat di butuhkan adanya transformasi pendidikan. Sekarang,pendidikan sudah harus merujuk kepada adanya konsekuensi logis dan berbagai perubahan perilaku,sikap,dan tata budaya. Bila melihat ruang hidup keagamaan dewasa ini,ternyata tidak lagi berwajah tunggal (berwajah banyak). Dengan demikian,pendidikan dan pengembangan jati diri yang berparidgma asketis dapat menjadi salah satu upaya transformasi alternatif menuju penumbuhan hikmat dan disiplin. ${ }^{3}$

Dalam filsafat, asketisme diartikan sebagai prinsip tingkah laku bermati raga demi memperoleh kebahagiaan,keluhuran moral dan idealisme kehidupan agama. Versi kuat;sikap menolak keinginan-keinginan tubuh dan dunia yang sifatnya dasariah,seperti nafsu birahi,keinginan memiliki harta

\footnotetext{
${ }^{3}$ Rannu Sanderan, “EXEMPLARY, MENEMUKENALI KUNCI PENDIDIKAN KRISTEN BAGI ANAK DALAM KELUARGA DAN PEMBELAJARAN AGAMA DI SEKOLAH" (n.d.).
} 
benda,kemasyuran dan prestasi. Hanya dengan cara ini seseorang dapat membebaskan jiwanya guna mencapai kebaikan dan keselamatan. ${ }^{4}$

2. Pengembangan jati diri seseorang

Perkembangan teknologi komunikasi pada era digital ini, pada satu pihak memberikan informasi-informasi yang sangat bermakna, khususnya di dalam bidang ilmu pengetahuan dan teknologi modern. Namun dipihak lain, dengan adanya perkembangan teknologi komunikasi ini telah membawah serta informasi-informasi negative yang merusak akhlak dan karakter manusia. Penyebaran informasi yang demikian tentu sangat berpengaruh bagi sikap dan karakter seseorang. Oleh karena itu, mengenai hal tersebut di situlah terjadi pengembangan jati diri seseorang dan pendidikan Kristen tidak boleh tinggal diam melihat hal tersebut. ${ }^{5}$

3. Bentuk pengembangan jati diri seseorang yang ditinjau dari perspektif Kristen

Pengembangan jati diri dalam pendidikan Kristen harus menjadi teladan yang baik dalam membentuk karakter dan jati diri seseorang. Kita harus memberikan teladan yang baik yang bisa ditiru oleh oleh orang lain sehingga lewat keteladanan itu bisa membentuk karaktek dan jati diri seseorang. Peneladanan berpadanan dengan konsep menyimak/mengamati dan menirukan sebagai salah satu aspek dari teori pendidikan Kristen. Keteladanan dapat memupuk pertumbuhan

\footnotetext{
${ }^{4}$ Sanderan, "DISIPLIN ASKETISME DAN HARMONI KONTRIBUSI DISIPLIN DIRI BAGI PENGEMBANGAN PENDIDIKAN KRISTEN."

${ }^{5}$ Rannu Sanderan, “Pesan Perdamaian Melalui Literasi Digital” (n.d.).
} 
kepribadian Kristen. Keteladanan dapat memupuk pertumbuhan kepribadian dan karakter jika para murid telah memiliki modal dalam bentuk antusisme. Pendidikan Kristen dan pengembangan jati diri seseorang dalam berbagai bentuk studi kristiani lainya,sepatutnya membantu siswa dalam mengemban jati diri dan sanggup menginterpretasi suatu gambar,menilai suatu keyakinan mengevaluasi sendiri nilai-nilai tentang alam dan lingkungan yang terus menerus dalam gereja maka senantiasa pula diperlukan perubahan fundamental dalam membangun stuktur pendidikan agama. ${ }^{6}$

Upaya untuk membentuk intuisi sebagai salah besar bagi nilai-nilai kebenaran Kristen menyadarkan bahwa betapa besarnya tanggung jawab dalam mengembangkan jati diri dan mendidik anak-anak Tuhan di dunia maya agar dalam bentuk kanal informasi-informasi sesat seolah suci,namun siap memangsa ataupun menyesatkan setiap anak Tuhan khususnya dalam mengembangkan diri dalam pendidikan Kristen. ${ }^{7}$

\section{KESIMPULAN:}

Perkembangan zaman yang semakin modern sudah mulai mengikis karakter dan jati diri seseorang. Oleh karena pendidikan Kristen harus bisa mengatasi hal tersebut, dengan mengembangkan jati diri seseorang dengan baik. Pendidikan agama Kristen, memiliki andil dalam proses pembentukan karakter,sebab agama memberikan bimbingan dan control sosial kepada manusia. Melalui pengembangan jati diri ,seseorang tidak hanya menjadi lebih baik,tetapi juga mampu menkontribusi secara positif bagi masyarakat dan sesamanya. Jati diri seseorang adalah proses penumbuhan dari pengembangan nilai-nilai luhur yang tercermin dari sikap sopan dalam penggunaan

\footnotetext{
${ }^{6}$ Rannu Sanderan, "Heuristika Dalam Pendidikan Karakter Manusia Toraja Tradisional," BIA': Jurnal Teologi dan Pendidikan Kristen Kontekstual3, no. 2 (December 19, 2020): 306-327, http://www.jurnalbia.com/index.php/bia/article/view/213.

${ }^{7}$ Rannu Sanderan, "INTUISI: Pendalaman Gagasan Hans-George Gadamer Tentang Intuisi Sebagai Supralogika," Jurnal IImiah Religiosity Entity Humanity (JIREH) 2, no. 2 (December 23, 2020): 114-125, https://ojs-jireh.org/index.php/jireh/article/view/39.
} 
bahasa. Pengembangan jati diri seseorang memampukan ia berpikir lebih panjang dsalam membuat perencanaan dalam hidupnya. Pengendalian diri dalam menunda atuu

menolak sesuatu yang kurang bermanfaat untuk sesuatu yang lebih berguna dan membahagiakan memerlukan proses latihan melalui pendidikan disiplin kendali diri.

DAFTAR PUSTAKA

Sanderan, Rannu. "DISIPLIN ASKETISME DAN HARMONI KONTRIBUSI DISIPLIN DIRI BAGI PENGEMBANGAN PENDIDIKAN KRISTEN” (n.d.).

---. "EXEMPLARY, MENEMUKENALI KUNCI PENDIDIKAN KRISTEN BAGI ANAK DALAM KELUARGA DAN PEMBELAJARAN AGAMA DI SEKOLAH" (n.d.).

---. “Heuristika Dalam Pendidikan Karakter Manusia Toraja Tradisional.” BIA': Jurnal 
Teologi dan Pendidikan Kristen Kontekstual 3, no. 2 (December 19, 2020): 306-327. http://www.jurnalbia.com/index.php/bia/article/view/213.

---. "INTUISI: Pendalaman Gagasan Hans-George Gadamer Tentang Intuisi Sebagai Supralogika." Jurnal IImiah Religiosity Entity Humanity (JIREH) 2, no. 2 (December 23, 2020): 114-125. https://ojs-jireh.org/index.php/jireh/article/view/39.

---. “Pesan Perdamaian Melalui Literasi Digital” (n.d.).

---. "Stratifikasi Sosial Kepemimpinan Tradisoanal Dalam Dinamika Demokrasi Modern" (n.d.). 